in NICO, B. \& MORAIS, J. (2001). "A Educação à Distância para uma Escola Global: o caso do Alentejo". in Manuel Patrício (Org.). Escola, Aprendizagem e Criatividade. Porto: Porto Editora.

\title{
A EDUCAÇÃO À DISTÂNCIA PARA UMA ESCOLA GLOBAL: O CASO DO ALENTEJO
}

\author{
JOSÉ BRAVO NICO \\ PEDRO MORAIS \\ DEPARTAMENTO DE PEDAGOGIA E EDUCAÇÃO DA \\ UNIVERSIDADE DE ÉVORA \\ E \\ NÚCLEO DE ENSINO E FORMACCÃO À DISTANCIA DA \\ UNIVERSIDADE DE ÉVORA
}

\section{INTRODUÇÃO}

Na suas múltiplas funções sociais. a "escola" tenderá a assumir um protagonismo cada vez mais preponderante em duas dimensões vitais para as sociedades humanas: a generalização do acesso ao conhecimento e a luta contra a exclusão, através de um sério investimento no capital mais fundamental que há: o capital humano.

Uma escola sem barreiras, uma escola de liberdade. uma escola de tudo para todos. Uma escola das pessoas, para as pessoas e pelas pessoas. Utopia ou não, pensamos ser este, o grande princípio orientador de qualquer sistema educativo de qualquer país. de qualquer cultura, $\mathrm{em}$ qualquer época, em qualquer contexto civilizacional.

Todos têm o direito de aprender. De aprender de acordo com as suas características fïsiológicas, intelectuais, volitivas, afectivas e vocacionais. Todos deverão ter o mesmo acesso à educação, independentemente da sua condição económico-social, do local onde residam ou da profissão que exerçam. A educação deve ser um bem universalmente acessível, sem excepções de qualquer índole.

Se estes princípios, no plano teórico, serão, eventualmente, pacíficos, já na sua dimensão prática se revelam inconcretizáveis.

Na realidade. são muitas as pessoas que nunca acederam aos sistemas formais de educação, e muitos são também os que, acedendo ao sistema, a ele se não conseguem adaptar e dele saem, de forma precoce.

Inúmeros são aqueles que não desistindo de percorrer um determinado percurso académico, dele não retiram proveito, quer do ponto de vista profissional, quer no que diz respeito à sua realização pessoal e social, muito menos no que se relaciona com o respeito pela sua dignidade de ser humano e pelo seu inalienável direito à felicidade. 
Deve ser. portanto, papel dos diversos sistemas que proporcionam educação responder às novas necessidades, expectativas e projectos de uma socicdade em célere processo de cvolução e de mudança. A escola não se pode afastar das pessoás c das suas realidades concretas, sob pena de ficar irremediavelmente num inconcebível, mas real. estado de obsolência.

Tentando encontrar algumas respostas a estas e outras questões, tão ou mais importantes que estas, os sistemas de ensino têm tentado procurar novas formas de proporcionar uma educação efectiva a cada vez mais pessoas. De facto, verifica-se que, nas últimas décadas, existe uma preocupação cada vez mais evidente de potenciar o desenvolvimento de todas as formas possíveis de educação, a todos os níveis, através da utilizaçâo de novas abordagens pedagógicas que envolvem metodologias cada ve\% mais diversificadas, com o recurso a uma tecnologia cada vez mais poderosa e capaz. de superar obstáculos outrora intransponíveis (barreiras geográficas. comunicacionais, etc.).

A utilização de estratégias de educação à distância, tem assumido um papel cada vez mais importante nos sistemas de educação. de cada vez maior número de países, representando uma forma alternativa e supletiva de acesso à educação por parte de todos aqueles que, de outra forma, dificilmente poderiam exercer esse direito, que todos temos, c que é o de aprender, como, quando e onde quisermos.

Numa região predominantemente rural como o Alentejo, a educaçâo apresenta necessidades básicas facilmente detectáveis. O reduzido índice de acesso à educação tem sido desde sempre o principal obstáculo a um desenvolvimento adequado da regiào alentejana. Existe uma alta taxa de analfabetismo, uma taxa clevada de abandono escolar, uma taxa de inaproveitamento escolar com uma dimensão considerável. O nível de qualificação académica e profissional dos alentejanos é dos mais baixos de toda a Europa. Uma realidade, de facto, muito difícil de aceitar.

Causa ou consequência desta situação, a desertificação humana nesta região é favorecida pelo reduzido dinamismo empresarial e pela atraç̧ão dos principais centros urbanos (CCRA, 1992), provocando um desenraizamento cultural da população e colocando o Alentejo na lista de regiões com menor PIB por habitante da União Europeia.

A educação à distância (EAD) surge assim como uma consequência inevitável da necessidade que existe em proporcionar educação em formatos adequados a quem dela necessita de forma tão evidente.

É impossível fazer com que as pessoas se desloquem de encontro à educação, uma vez que várias são as razões que impedem tal facto. Só existe, por enquanto, um caminho que reúne alguma viabilidade: levar a educação de encontro aqueles que dela necessitam e que, simultaneamente, a desejam.

É devido a esta simples conclusão que surge em 1995, na Universidade de Évora, o Núcleo de Ensino e Formação à Distância (NEFAD).

Pretende-se deste modo, ao implementar actividades deste tipo, reduzir o fosso existente entre as áreas mais rurais e os núcleos urbanos de maior dimensão, e por conseguinte proporcionar um importante contributo para um efectivo desenvolvimento da região. 


\section{IMM NOVO CONClITO DE EDUCAÇÃO}

Educaçẫo é uma palavra difícil. Nela se reúnem coisas tão importantes como o ensino e a aprendiagem. Virtualmente duas dimensões de uma mesma realidade, mas por vezes, duas realidades bem distantes e até mesmo inconciliáveis. A empresa educativa, tal como a define Chené (1985, p. 29), ou seja, a transformação dos sujeitos sociais num determinado momento da sua história, tarela que tem, cla própria, uma história e que consiste em sair de um estado definido para conseguir atingir um novo estado, tem vindo a sofrer modificaçôes profundas, nomeadamente com o aparecimento da chamada sociedade da informação.

A crescente quantidade de informaçăo necessária para qualquer actividade e o facto desta se encontrar cada vez. mais disponível, fizeram com que os tradicionais sistemas de formação sé encaminhem rapidamente para um estado de semi-obsolência, do qual nâo têm tomado a devida consciência e de que não sairão tão rapidamente quanto o descjável. De facto, se no séc. XVII, o saber diminuia metade do seu valor no puríodo correspondente a de gerações, já no início do nosso século, o conhecimento adquirido por um aluno universitário, durante o seu curso, conservava apenas melade do seu valor no final da sua carreira profissional. Actualmente, as informações adquiridas e nâo actualizadas desvalorizam-se cerca de $50 \% \mathrm{~cm}$ cada período de 6 anos, isto é $97 \%$ no espaço de uma geração (Rocha, 1988, p. 202). É, pois, por demais evidente a premencia de adaptar os sistemas de ensino a esta nova realidade que se caracteriza pelo reduzido tempo de vida útil do conhecimento e também pela urgentíssima necessidade de repensar os conceitos de escola. de educação, de ensino, de aprendizagem, de docente e de discente.

A escola do futuro, será necessariamente uma escola mais global. Una escola de tudo para lodos. Uma escola, na qual a sala de aula não se poderá resumir a uns poucos metros quadrados limitados por barreiras físicas. Uma sala de aula onde, a algumas das características que se the reconhecem actualmente, como a multidimensionalidade, simultaneidade, imediaticidade, imprevisibilidade, publicidade e historicidade (Moreira, 1993, p. 58) se adicionarão outras, como por exemplo a virtualidade. A sala de aula será onde se encontrar alguém que aprenda, seja de que forma for. com que objectivo tiver em mente.

A escola lenderá também a assumir um novo protagonismo na detecção de falhas sérias no desenvolvimento daqueles que aprendem. São esse tipos de estudos, que revelam esse tipo de carências educacionais, que fornecerâo a base de tum auténtico processo de seleç̧ão de objectivos na educação, a base mais correcta de gualquer processo de desenvolvimento curricular (Tyler, 1976, p. 8).

No seio desta nova escola, reflexiva, crítica, aberta, democrática, livre, disponivel. operando de forma adequada sobre a realidade contemporânea, acompanhando e influenciando o próprio progresso, sendo motora da mudança social, trabalhando sempre com a finalidade da formação completa e integral da pessoa humana, o professor será, necessariamente chamado a assumir novos papéis ou, a desempenhar os scus papéis de sempre, de uma forma mais criativa e eficaz. Sem perder o seu papel de perito num dado ramo do conhecimento, o professor tenderá, no gresente e no futuro, a assumir-se como um assistente ou um gestor de aprendizagens. fletá de possuir competências específicas no âmbito do desenvolvimento curricular, de forma a desempenhar de forma eficaz a função de programador e executor do 
currículo, de modo a adaptá-lo às novas realidades ambientais e sociais (Estrela, 1992. p. 35). A sua tarefa prioritária, como formador, consistirá na organização adequada do meio em que o sujeito em formação desenvolve a sua acção (Berbaum, 1993, p. 19).

Esta nova escola e esta nova representação de professor, exigirá, da parte destes últimos, as necessárias mudanças em termos de atitudes e de comportamentos, de forma a que a sua acção formadora tenha maior rendimento e maior eficácia.

Exige-se, pois, um novo perfil de professor. Um novo professor, para uma nova cscola, uma vez que, cada vez mais, existem novos alunos. Indivíduos com necessidades especílicas de formação, incompatíveis com a oferta proporcionada pela escola tradicional, com a palavra presencial do mestre, com as brutais cargas horárias lectivas que se verificam actualmente. Novos alunos, com maior grau maior liberdade na seu processo personalizado de gestão da sua aprendizal, cada vez menos adeptos de um escolha da sua propria trajectória academica indivis os sistemas educativos têm obrigação ensino magistral, presencial, ascetico e liga de aluno. O próprio conceito de adaptação de se adaptar a este novo paradigideração com as pretensões dos indivíduos, as suas pressupõe que se entre em consideraçăo com as préficos de cada situação, necessidades, as suas expectativas, os condicionalida das sociedades a que pertencem num determinado mo

Nesta escola glohal, e virtualmente acessível a todos, a aprendizagem autónoma revelar-se-á, eventualmente, como uma das formas fundamentais de promover a mobilidade e a conquista de novas estruturas intelectuais, ao nível de quem percorre essas trajectórias de formação (Fernandes, 1990, p. 128).

De facto, com a promoção desta nova valência na escola, associándo-a ao conceito de autonomização, surge um novo, e significativo, poder: o poder do formando se apropriar do destino do seu próprio processo pessoal de formação (Pineau, 1985, p. 32)

A uma nova escola, corresponde um novo mapa pedagógico-estratégico. A escola do futuro é uma escola de educação total, existe onde está quem aprende, deve atender prioritariamente as suas necessidades de formação, deve promover a autonomia na gestão dos processos individuais de aprendizagem, deve assumir-se como virtualmente acessível a todos, tendencialmente universal, livre e democrática.

\section{A EDUCAÇÃO À DISTÂNCIA NUMA ESCOLA ABERTA}

A EAD define-se como uma modalidade de ensino/aprendizagem em que os educandos se encontram separados, no tempo e/ou no espaço, dos educadores desenrolando-se o processo comunicacional através de um ou mais meios. Desde a sua origem no Reino Unido, em 1840 (Rowntree, 1992, p. 8), através da comunicação por correspondência. a EAD tem recorrido a diferentes técnicas, meios de comunicação e estratégias de ensino/aprendizagem, até chegarmos, actualmente, ao uso generalizado do multimédia, da informática e das telecomunicações avançadas, com potencialidades de trabalho mais atractivas e maior eficiência na aprendizagem.

A EAD apresenta-se como uma alternativa ou um complemento aos actuais métodos de educação, com capacidades de resposta a diversos tipos de necessidades, em particular para pessoas impossibilitadas de participar nas actividades educativas 
existentes, por motivos de âmbito espacial e/ou temporal ou pela inexistência de programas adequados às suas necessidades. Deste modo, podemos referir a EAD como um elemento de dinamização com especial importância numa pointi desenvolvimento para as áreas mais rurais décias de EAD recorre-se a um conjunto vasto

Para o desenvolvimento de estrateglas de EAD recte integrados no sistema de de meios e de produtos, que devem ser cuidemos incluir os seguintes meios:

ensinolformação à distância.

b) Formação baseada no computador;

c) Emissōes de rádio e TV (por satélite ou via terrestre) com ou sem interacção

entre o centro emissor e os locais de recepção;

d) Produtos audiovisuais e multimédia;

e) Telecomunicações, telemática e teleconferência.

Com o recurso às novas tecnologias de comunicação e à informática, os actuai istemas de EAD deram um salto importante em termos de possibilidades de interactividade entre o educador e o educando e entre os propró possível dar apoio simultâneo a grupos de meios de comunicação bidireccionais, é poar através de teleconferência, reuniões localizados em locais dispersos ou m

escolha e combinação de entre uma infinidade de

alvo de uma análise das alternativas e de conjugação de meios e técuicas, das vantagens e desvantagens das condiçoes especíticas do contexto em ecomo dos conhecimentos para trabalhar com tecnologias e recursos disponiveis, bem comsiderar que o acesso dos destinatários às essas tecnologias. No entanto, devem particularmente importante a ter em conta na diversas tecnologias é um ar. Na EAD, o acesso e a disponibilidade da tecnologia a escolha dos meios a utilizar. Nancipal factor de avaliação do potencial de uma estratégia (Bates, 1995, p. 37)

Do vasto conjunto de tecnologias a que um sistema de EAD pode recorrer. devemos ainda destacar as potencialidades da informática. $O$ papel do computador ferramenta multifuncional é particularmente importante nos nossos dias, pois não só constitui um precioso auxiliar educativo, como é também uma tecnologia presente em quase todas as actividades profissionais

$\mathrm{Na}$ EAD encontramos três tipos principais de utilização do computador:

Instrumento de aprendizagem através de aplicações educativas

Nesta utilização podemos incluir os diversos tipos de software educativo, o ensino assistido por computador e os produtos multimédia e hipermédia. A utilização da informática na educação contribui para a motivação na aprendizagem e aumenta as possibilidades de interacção entre o educando e o material pedagógico.

Por outro lado, algumas tarefas educativas como a correcção de testes, podem ser automatizadas num sistema informático, com a vantagem de proporcionar maior rapidez nos resultados (Stander, 1990, p. 197). 
b) Instrumento de comunicaçäo

Quando ligamos um computador a uma rede informática obtemos um vasto potencial de comunicação e interactividade, ideal para manter em contacto ducandos e educadores. De facto, a interactividade é indicada como a principal vantagem dos sistemas de comunicação por computador (Mason. 1994, p. 57).

Nestes sistemas onde o educador é normalmente representado por um pacote de materiais de aprendizagem, tendo em vista superar a falta de contacto humano, a informática permite desenvolver diversas formas de apoio aos educandos. Pode-se assim proporcionar discussões em grupo e fornecer apoio ao estudo, complementando os diversos materiais de estudo e dando o acesso a um vasto mundo de informação.

Numa estratégia de implantação regional de centros locais de estudo e de apoio aos educandos, deve ser contemplada a instalação de uma rede informática que possibilite um contacto rápido entre todos os intervenientes. Estes centros são locais onde se fomenta o trabalho de grupo e as relaçóes entre educador e educando. sendo simultaneamente um local de convívio, divulgaçâ, estudo e apoio à aprendizagem.

c) Ferramenta para a produção de materiais escritos e para a gestão da EAD A utilização de ferramentas de DTP (Desk Top Publishing) permite o desenvolvimento e produção de materiais impressos de grande qualidade $\mathrm{e}$ com elevada eficácia. Este trabalho, realizado normalmente por equipas multidisciplinares, implica um percurso dos materiais por diferentes especialistas, sendo portanto o suporte informático ideal para este processo.

Importa também realçar a importância do uso da informática na gestão dos sistemas de EAD por forma a oferecer um funcionamento eficiente aos seus utilizadores. O estado actual de utilização da Internet não nos deixa dúvidas de que estamos perante um meio que irá influenciar a produção e disponibilização de produtos de EAD, assim como no que se refere à adopção do computador como instrumento de aprendizagem. Para além de ser uma porta aberta para um mundo de informação. essencial ao processo de aprendizagem, a Internet permite a oferta de todos os tipos de utilização apontados para os meios informáticos com características de acessibilidade cada ve $\%$ maiores

Será também de referir que estas estratégias implicam a utilização do tecnologias relacionadas com um estilo de vida moderno, onde a rentabilização do tempo assume um papel cada vez mais importante. Neste âmbito, será de referir a crescente procura de possibilidades de educação mais individualizadas, com a possibilidade do educando escolher por si o processo e o passo de aprendizagem que melhor se adequa ao seu estilo ou que se encontra dentro das suas possibilidades.

UMA ESCOLA GLOBAL PARA O ALENTEJO

Quando falamos de implementação de actividades de EAD em Portugal, encontramos um desconhecimento e um receio generalizado sobre estas estratégias de 
ensino, sendo que as pollas experiências desenvolvidas nos úlimos anos concentram- se quase exclusivamente nos grandes centros urbanos do litoral. No Alentejo muito pouco tem sido feito neste campo. embora, no entanto, possamos reconhecer que a utilizaçâ destas estratégias constitui uma importante forma de proporcionar oportunidades de educação em contextos de forte ruralidade.

Assim. e tendo cm vista a implementação de actividades de EAD no Alentejo, apresentamos no quadro seguinte, alguns elementos de uma análise "SWOT" (Pontos Fortes. Fracos. Oportunidades e Ameaças). Indicada como importante para um ensino aherto (Hunter, s.d. p. 15). esta análise de marketing, possibilita a identificação dos principais aspectos da introdução de um produto num mercado competitivo. Dos cesultados desta análise, devemos realçar e fomentar a aplicação dos pontos fortes. eliminar on pelo menos reduzir os pontos fracos, para que o sistema possa ser melhorado, detectar e aproveitar rapidamente as oportunidades que existem no contexlo de aplicaçầo e. por último. defendermos o sistema face às ameaças que podem intluenciar negativamente o funcionamento das actividades.

\section{QUADRO 1}

ANÁl ISE SWOY PAR A A IMPLEMENTAÇÃO DE EAD NA REGIÃO ALENTEJO

\begin{tabular}{|c|c|}
\hline I:OR'IES & FRACOS \\
\hline 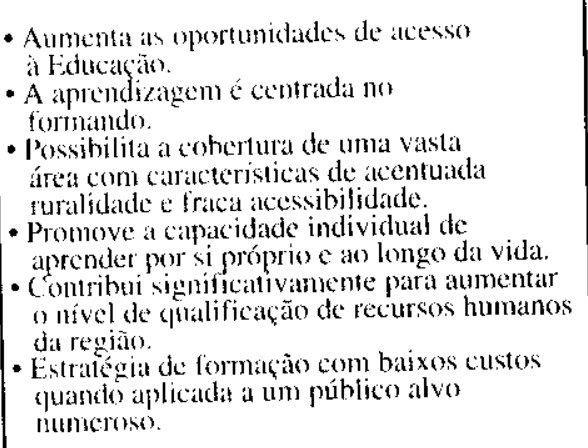 & $\begin{array}{l}\text { - o fornando deve possuir grande } \\
\text { capacidade para gerir o seu tempo e as } \\
\text { suas capacidades de aprendizagem. } \\
\text { - São necessários elevados custos iniciais. } \\
\text { - Escasse'z de experiências anteriores. } \\
\text { - Necessidade de reunir equipas técnicas } \\
\text { interdisciplinares para o design dos } \\
\text { sistemas e a produção de materiais. } \\
\text { - Necessidade de constituir inicialmente } \\
\text { um sistema complexo de distribuição } \\
\text { de produtos e apoio a formandos. } \\
\text { - A redurida cooperação existente entre } \\
\text { as instituiçoes que potencialmente } \\
\text { poderão participar nestes sistemas. }\end{array}$ \\
\hline OPORTINIDADLES & AMEACAS \\
\hline 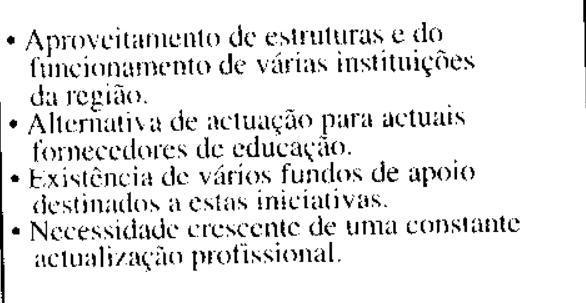 & $\begin{array}{l}\text { - Formas tradicionais de educação. } \\
\text { - Instituiçôes que "monopolizam" } \\
\text { actividades de educaçĩo a nível local } \\
\text { ou sectorial e que se encontran } \\
\text { indisponiveis para trabalhar com EAD. } \\
\text { - Resistência por parte dos potenciais } \\
\text { destinatários destas actividades. } \\
\text { - Dificuldades no estabelecimento de } \\
\text { esquemas regionais baseados na } \\
\text { cooperação entre instituições. }\end{array}$ \\
\hline
\end{tabular}


Tendo em conta a falta de recursos financeiros e de recursos humanos necessários para o arranque de sistemas desta natureza, ć fundamental que seja feito um esforço para a criação de uma rede de cooperação entre as diversas entidades interessadas em participar neste sistema. Por outro lado, o elevado custo de elaboração de um produto de formação e a necessidade de obter um grupo de destinatários com dimensão suficiente para rentabilizar o investimento, leva a que a variável económica possa ser considerada um elemento chave no processo de ligação entre diversos fornecedores de educação.

A EAD pode contribuir para uma democratização do conhecimento através da igualdade de oportunidades de educaçăo dentro de toda uma região, fomentando a abertura de portas de comunicação e contacto com outros contextos através da utilização das tecnologias implicadas no processo.

- com base nos pressupostos aqui apresentados que a Universidade de Évora. através do NEFAD, se encontra a preparar um esquema de actuação com vista à implementação de actividades de EAD numa base regional.

\section{BIBLIOGRAFIA}

BATES, A. (1995). Technology. Open learning and distance education. Londres. UK, Routledge.

BERBAUM, J. (1993). Aprendizagem e formação. Porto. Porto Editora.

CHENÉ, A. (1985). «Les cycles de vie et léducation des adultes». In: Matthias Finger e Christine Josso (eds). Pratiques du récit de vie et théories de la formation. Section des Sciences de l'Éducation de l'Université de Genève. pp. 9-24.

ESTRELA, M. T. (1992). Ralação pedagógica. Disciplina é indisciplina na aula. Porto. Porto Editora.

FERNANDE, E. (1990). Psicologia da adolescencicia e da relação educativa. Porto. Edições Asa.

HUNTER, lan: BEESON, David (s.d.). Marketing open and flexible learning... The direct mail approach. Durstable. UK. Natthe Open Learning Sector.

MASON, R. (1994). Using communications media in open and flexible learning. Open and distance learning series. Londres. UK. Kogan Page.

EIRA, João Manuel (1993). Desenvolvimento profissional dos professores: a evolução das preocupaçôes e motivações profissionais. Dissertação apresentada para as provas de aptidão pedagógica e capacidade científica. Lisboa. Faculdade de Psicologia e de Ciências da Educação da Universidade de Lisboáa.

PINEAU, Gaston (1985). «Pour une théorie tripolaire des formations vitales pour soi. les autres et les choses». In: Mathias Finger e Christine Josso (eds). Pratiques du récit de vie et théories de la formation. Genève. Section des Sciences de l'Éducation de l'Université de Genève. pp. 25-40.

C. Marcel (1984). A relação pedagógica. Coimbra. Coimbra Editora.

ROWNTREE, Derek (1992), Exploring open and distance learning. Londres. UK Kogan Page.

STANDER, Brigitte-Maria (1990). «Computer-marked assignments. Status and prespectives". In: Media and technology in european distance education. Editado por A. Bates. Milton Keynes. UK. Eadtu.

TYLER, R. W. (1976). Princípios básicos de currículo e ensino. Porto Alegre. Editora Globo. 